\title{
NOTAS FILOLÓGICAS EN TORNO A LAS POESÍAS DE LUIS MARTÍN DE LA PLAZA*
}

En Los 1,001 años de la lengua española (México, 1989), p. 166, dedico unas líneas a las Flores de poetas ilustres, "manifiesto de la nueva poesía" (la posterior a Herrera) que Pedro Espinosa imprimió en 1605. Si se piensa, digo, que en esas Flores está "la primera edición de poesías [de Góngora, Quevedo, etc.], y que muy a menudo las obras de un poeta no se publicaban en vida suya..., es deplorable que no haya habido más antologías impresas" (como las hubo en Italia). Recordando, además, lo ufano que se muestra Espinosa por su labor de selección -como dice en el gracioso prólogo Al lector: "para sacar esta Flor de harina he cernido dozientos caýzes de Poesía"-, añado que, al lado de las poesías de quienes iban a ser famosos, Espinosa publicó las de poetas que no tuvieron esa suerte, pero que en 1605 se medían con las de ellos, en particular "las del extraordinario Luis Martín de la Plaza”. Es un elogio que me salió del corazón ${ }^{1}$. Y me ha causado gran sorpresa el verlo citado por Jesús Morata, pues yo pensaba que ese libro mío no tenía, como quisiera, lectores en España. (Es posible que para Morata haya sido sorpresa toparse con un elogio que venía, no de un antequerano, sino de un lector hispanohablante común y corriente.)

* A propósito de: Luis Martín de la Plaza (1577-1625), Poesías completas. Ed., introd. y notas a cargo de Jesús M. Morata Pérez. Pról. de José Lara Garrido. Diputación Provincial, Málaga, 1995; 315 pp.

${ }^{1}$ Desde hace tiempo doy en la Universidad de México un seminario de "Poesía de los siglos de oro (de Garcilaso a Sor Juana)", que consiste fundamentalmente en una lectura cuidadosa (close reading) de los textos. El recorrido, en orden más o menos cronológico, dura cinco o seis años. Una de mis alegrías es ver a estudiantes que, aun cubiertos ya sus "créditos" curriculares, me acompañan a lo largo de esos años. Y, cuando le llega el turno a Luis Martín, otra alegría es oír cómo los estudiantes (graduados), que no lo conocían ni de nombre, prorrumpen en un “¡Pero qué buen poeta!” (La próxima vez, en lugar de las copias xerox que saco para ellos, los estudiantes podrán adquirir la edición que aquí comento.) 
Así, pues, la aparición de las Poesías completas del "extraordinario" poeta -"Es ésta, dice Morata, la primera vez que se editan, juntas, todas las poesías de Luis Martín de la Plaza"- es, para mí, un acontecimiento sumamente jubiloso. Y siento que la mejor prueba del interés con que he examinado esta edición, y de la importancia que le reconozco, son las observaciones críticas que siguen. El prólogo de José Lara Garrido me hace saber que está en preparación "lo que será la definitiva editio maior". Me hago la ilusión de que alguna de mis observaciones podría ser tomada en cuenta, ad maiorem Ludovici Martini gloriam, en esa editio maior.

Tres son las fuentes principales de las 142 poesías que se editan: las Flores de Espinosa (E), su "padre compañero", o sean las Flores de Calderón $(\mathbf{C})$, y los tres primeros tomos del manuscrito llamado Cancionero antequerano (A). Hay 29 poesías en $\mathbf{E}, 48$ en $\mathbf{C}$ y 129 en $\mathbf{A}$. Casi todas las de $\mathbf{E}$ y $\mathbf{C}$ están asimismo en $\mathbf{A}^{2}$. Morata decidió tomar A como texto-base en todos los casos, por tres razones: 1) el gran número de poesías que contiene; 2) "el rigor y la claridad del copista"; y 3) la "probable supervisión" del poeta. De hecho, como luego haré ver, el copista de A no es siempre riguroso (y, por lo demás, el rigor y la claridad no faltan en $\mathbf{E}$ y en $\mathbf{C}$ ). En cuanto a la "probable supervisión", hay un fuerte argumento en contra: los errores de A nunca están corregidos por una segunda mano. La única razón que cuenta es la primera; y yo añadiría esto otro: A es bastante posterior a $\mathbf{E}$ y a $\mathbf{C}$, de manera que es lógico que contenga retoques y muestre el "estado final" de algunos poemas $^{3}$. Añade Morata que $\mathbf{E}$ y $\mathbf{C}$ "complementan (y apenas rectifican) las lecturas de A”. Para que no se entienda que estas dos

${ }^{2}$ Con excepción de cinco que se leen sólo en $\mathbf{E}$ (entre ellas, el famoso madrigal "Iba cogiendo flores...") y de cuatro exclusivas de C. En cambio, las exclusivas de $\mathbf{A}$ son 61. Es notable el número de poesías que en $\mathbf{A}$ se copian dos veces, y hasta tres (núms. 7y 53), a menudo con variantes.

${ }^{3}$ Un caso muy claro es la canción "Vuelvo de nuevo al llanto..." (núm. 105). Varios son aquí los pasajes retocados, en particular los vv. 49-64, que dicen en E: "Aquí estoy esperando / que el sol coja sus hebras de oro puro, / y salgo luego, cuando / su negra sombra pone al mundo obscuro, / y aqueste campo riego / con agua de mis ojos, que es de fuego"; Luis Martín debe de haber visto que "su negra sombra" (la sombra ¡del sol!) era un despropósito, y corrigió a fondo: "...cuando / la noche vuela por el aire oscuro, / y dan al campo luego / agua mis ojos y mi boca fuego" (A). Otro ejemplo: el v. 55 del núm. 117 dice en E "en la muerte tristísima, y la fama”, verso que, según el esquema de las estancias, debiera ser heptasílabo, y corrigió: "en la muerte, y la fama". (Para aligerar la tipografía traduzco a arábigos los números romanos de las composiciones, y los pongo en cursiva.) 
fuentes son posteriores, en vez de "apenas rectifican" sería mejor decir que hay casos en que el copista de $\mathbf{A}$ se equivocó, y que por fortuna puede enmendarse el yerro a base de $\mathbf{E}$ o de $\mathbf{C}$. En realidad, hay no pocos casos en que la edición de Morata es ecléctica. En el soneto 2, por ejemplo, ha desechado la lección de $\mathbf{A}$, "el arquitecto labra en sueño vano", y ha preferido la de $\mathbf{C}$, "labraba el arquitecto sueño vano", ciertamente más satisfactoria. Este mismo sano eclecticismo debiera, según yo, practicarse en casos como los que detallo a continuación:

14: Soneto que desarrolla el tópico 'Cuando entono tu nombre, todo se inmoviliza para escucharlo': "Veo... parar los ríos..., callar los montes", etc. Es lo que se lee no sólo en E, sino también en la segunda de las dos versiones de A. Lo que dice la primera versión de A es "correr los montes", lectura que no viene al caso. Me extraña que Morata la haya preferido.

22: un peñasco, "fortaleza / que ardientes rayos reparar se atreve". Peñasco que "se atreve reparar rayos", no puede ser. La lección buena está en C: "a parar se atreve". (El peñasco que no deja pasar los rayos del sol se parece a las puertas de la torre de Dánae, en 66, que "niegan paso" al sol y al viento.)

32: "adorado cabello" es error evidente de A. En $\mathbf{C}$ se lee dora$d o$, que es lo que aquí conviene: el cabello rubio está en serie con "el color rosado" de la tez.

94: "allá suenan acentos infinitos / ángeles" es frase que no se sostiene. Lo que se lee en $\mathbf{C}$ es diáfano: “...acentos de infinitos / ángeles".

111, estrofa 4: “AAy ligero contento, / cómo... / aumentas la ocasión, el sentimiento". El texto satisfactorio es el de C: "aumentas la ocasión $a l$ sentimiento". El contento es tan "ligero" (tan breve y fugaz) que, en vez de dar deleite, se convierte en una causa más para el sentimiento (doloroso) del amante.

114, v. 70: "tiemple en dulce risa alegre el pecho" es verso cojo. Para remediarlo, Morata imprime tiemple, con una diéresis filológicamente insostenible. El verdadero remedio está a la mano, en C: Desprecie el ánimo la ambición de riquezas, "y temple en dulce risa alegre el pecho / el llanto amargo". (Cf. 117, v. 25: "templa el rigor del frío".)

140, v. 12: "que cuanto escribas en historia ajena / por ti se dice" no tiene sentido. Una vez más, la lección correcta es la de C: "que canto escuchas..., / por ti se dice"4.

${ }^{4}$ El poema 130 figura en A y en dos impresos de 1615. En su v. 48, la “escon- 
En estos siete casos, pienso yo, debió hacer Morata lo que hizo en 60: la lección de $\mathbf{A}$ es "golpe fuerte / el arco de aguda si traidora flecha”, con un imposible verso de 12 sílabas, mientras que en $\mathbf{C}$ se lee "golpe fuerte / clavó de aguda...", que, además de hacer endecasílabo el verso, nos da el verbo de la oración. Morata, esta vez, imprime "golpe fuerte / [clavó] de aguda si traidora flecha".

Vale la pena decir algo sobre $\mathbf{C}$, esas Flores que, reunidas en 1611 por Juan Antonio Calderón, permanecieron inéditas durante casi tres siglos. El manuscrito original se hallaba a fines del siglo xix en la biblioteca del Duque de Gor, en Granada. Lo tuvo en sus manos don Juan Quirós de los Ríos, el cual lo describió con pelos y señales el enviarle a don Marcelino Menéndez Pelayo la copia que de él hizo sacar. De esta copia se valió don Francisco Rodríguez Marín para la muy tardía edición príncipe de Sevilla, 1896. Príncipe, y además única. ¿Cómo es posible que en este siglo de actividad editorial sin precedentes, con centenares de estudiosos -españoles y no españoles- de la poesía de los siglos de oro, nadie nos haya dado una edición basada en el manuscrito que fue del Duque de Gor? No puedo creer que ese manuscrito, reseñado tan en tiempo presente hace apenas un siglo ( $\mathrm{y}$ un siglo más o menos "civilizado"), se haya convertido en humo. Morata cita $\mathbf{C}$ por la edición de Rodíguez Marín, y tengo la impresión de que eso es lo que se hace siempre. Nadie, al parecer, ha acudido siquiera al ms. de la Biblioteca de Menéndez Pelayo. El texto que se usa ha pasado por dos intermediarios: quien copió el ms. original y quien copió la copia para mandarla a la imprenta. A uno de los dos, o a los dos, fatalmente se les habrán escapado errores. Yo tengo anotados algunos. Por lo que toca a las poesías de Luis Martín, he aquí varios ejemplos:

15: “¿Oyes, del golpe horrendo, el sol hinchado?” es un disparate, pues el sol no se "oye" (el responsable de este error se dejó llevar por el sol del verso siguiente). En A se lee: “¿Oyes del golpe horrendo el son hinchado?” (o sea el espantoso fragor de la tormenta).

110, v. 5: "y el contrario de la noche fría" es verso cojo. Tiene que ser, como en $\mathbf{A}$, "y el sol contrario de la noche fría".

114, w. 92-93: "y cabras y ovejas otras ciento / tienden el verde pelo a las dehesas" carece de sentido. Luis Martín no pudo

dida playa", como dice uno de los impresos (escondida, pero hasta allá llega el resplandor de la orden carmelita reformada por Santa Teresa), parece mejor que la "extendida playa", como dice $\mathbf{A}$. 
escribir eso, sino lo que se lee en A: "y de cabras y ovejas otras ciento / tunden el verde pelo a las dehesas" (bonita imagen: "tundir el pelo verde", 'pacer la hierba').

115, vv. 1-2: "Huye la nieve helada / del sol, quebrada la cerviz al toro" es otro error "clásico" de copista fatigado. En A se lee: "Huye la nieve helada / del sol que borda la cerviz al toro" (queborda leído como quebrada $)^{5}$.

122 ("Elegía al Cristo el Viernes Santo”), vv. 149-151: “Ay, no pierdas tu sangre en el arena! / Ya que yo soy tierra, no permitas / sea playa estéril y de abrojos llena". Para estos tercetos no hay más fuente que $\mathbf{C}$, pero no cuesta trabajo quitarle su cojera al v. 150. Lo que escribió Luis Martín tiene que haber sido "y ya que yo soy tierra, no permitas...", etcétera.

Paso ahora a las poesías que figuran únicamente en $\mathbf{A}$, de manera que la corrección de los yerros queda a cargo del "buen sentido". Ya dije que en $\mathbf{A}$ hay muchas poesías copiadas dos y aun tres veces. En estos casos Morata procede eclécticamente. El soneto 7 está sólo en A, pero en tres lugares distintos, o sea que hay de dónde escoger. En dos de las versiones el soneto comienza "Esparce confusión, dilata errores, / ;oh noche!...”; Morata ha escogido el comienzo de la otra versión: "Dilata confusión, esparce errores", y no hay sino respetar su decisión. Me detengo en algunos otros casos:

23: "que si vos no venís, será el remedio / para acarear mi mal venir mi muerte". Después de decir que este acarear "tiene poco sentido", añade Morata que "sería caligráfica y semánticamente posible acavar". Siendo así -y entonces el sentido es perfecto: 'Si vos no venís, el remedio para acabar mi mal será la muerte'-, no me explico por qué prefirió leer acarrear, que no tiene sentido.

${ }^{5}$ Morata registra tienden, quebrada, etc. entre las "variantes". Tal vez sería mejor poner estos disparates en saco aparte. Verdaderas variantes son "Las puertas eran..." (2) "Eran las puertas..."; "Adonde lava..., / allí quedó..." (60) "Aquí do lava..., / aquí quedó" (el segundo aquí se le escapó a Morata); "como si de oro y de cristal luciente" (12) "como si de cristal y oro luciente"; "los mortales ojos" (4) "los humanos ojos", etc. Tal vez también (aunque esto me parece dudoso) las alternancias esconde/asconde, ahora/agora, etc. Pero en cuanto a "variantes" como victoria/vitoria, obscura/oscura, de este/deste, hielo/yelo, viejo/biejo, yo creo que ni siquiera vale la pena registrarlas (y mucho menos derota/derrota o corrientes/corientes). "Se excluyen con frecuencia las [variantes] estrictamente caligráficas u ortográficas", dice Morata en la p. 58. ¿Por qué no excluirlas siempre? -A veces registra "variantes" que no lo son, pues dicen lo mismo que el texto editado (así 53, v. 14; 60, v. 12; 117, v. 17). 
104: Se habla de la diosa Astrea, que huyó de nuestro corrompido mundo y se refugió en el cielo. "Mas ¿quién... / reluce a Astrea, de la tierra ausente? / Vos, don Francisco...". Morata "supone" un error del copista: reluce en vez de reduce. ¡Pero claro! El error salta a la vista: don Francisco de Alfaro, corregidor de Antequera, es quien 'hace volver' (gongorinamente, reduce) la Justicia a la tierra. Cf. 125, v. 25, donde se le dice a Felipe II: "De ti por quien bajó del cielo Astrea". No creo que esté bien mantener "reluce" en el texto ${ }^{6}$.

He aquí los casos en que Morata corrige en el texto, a base de buen sentido, los errores de A:

28: "esplico el pecho", corregido en "[a]plico el pecho".

44: "se ablanda el agua" es absurdo. El pescador se dirige a un escollo: "Si con las olas que repite / te ablanda el agua, [así mi llanto ablandará a Nereida]". La corrección de Morata es absolutamente necesaria.

113, v. 16: "y ellos... el freno tascas", corregido en tascan.

123, v. 13: "Oh vos lo que pasáis", corregido en "los que pasáis".

125, v. 116: "con infamia nuestra de otomana gente" (12 sílabas), bien corregido: "con nuestra infamia de otomana gente".

128, v. 11: "hurtó al viento", corregido en "hurtó [e]l viento"7; y v. 45, "remeras ambas", corregido en "rémoras ambas".

En 128, vv. 60-62, el texto que imprime Morata dice:

Vuestras provincias, no, de gente extraña teman ya inundación, y las ciudades, [que] fiera arruina y furiosa enciende.

El error es obvio, pero la corrección no parece satisfactoria: la adición del pronombre relativo ("[que]") deja en el aire, sin verbo, la cláusula "y las ciudades...". Quizá sea mejor suponer que el copista interpretó un "q̃ las ciudades" como "y las ciudades". Así, la lectura que propongo es "...inundación [que] las ciudades / fiera arrüina y furiosa enciende".

${ }^{6}$ Es caso parecido al de 142 (véase infra, p. 438). Con referencia a San Ignacio y San Francisco Javier, se lee en el v. 43 que "sus almas a la Iglesia fueron almas". Morata cree probable que el segundo almas sea adjetivo ('vivificantes'), y "menos probable" que sea un error por armas. A mí, en cambio, me parece evidente que son armas lo que viene al caso. Véase el contexto: las almas de los dos santos fueron armas para la Iglesia, muros para los fieles, palmas para los combatientes. (La Compañía de Jesús es una milicia: cf. el soneto 81).

${ }^{7}$ Lo corregido, aquí y en 28 , va impreso entre corchetes. Tal vez debiera hacerse lo mismo en los demás casos: "[t]e ablanda”, "tasca[n]”, etcétera. 
Morata somete a crítica muy estrecha las correcciones hechas por Dámaso Alonso y Rafael Ferreres en su edición parcial del Cancionero antequerano (1950). He aquí los casos más notables:

88, v. 7: La primera de dos versiones dice cielo (repitiendo en rima el cielo del v. 2) y la segunda dice ielo. Morata rechaza la corrección suelo de Alonso-Ferreres, y con razón: "flores que jamás vio el hielo" es lectura satisfactoria.

119, v. 81: "su torpe vicio mira". Morata rechaza, también con razón, la enmienda "torpe vino".

126, v. 27: “un mil, un quento" (o sea un cuento, 'un millón'). La enmienda de Alonso-Ferreres, "un ciento", era evidentemente desacertada.

127, v. 34: "golpes le tira y su firmeza aprueba". Aquí la corrección de Alonso-Ferreres, "y su firmeza prueba" ('pone a prueba'), parece buena -en seguida se lee "probó tu fortaleza"-, pero Morata no la acepta.

128, v. 55: El poeta le pide al Océano que conduzca "a los cultos seres [San Ignacio y San Francisco Javier], / de eternas laureolas / comedidos...". Se entiende por qué Alonso y Ferreres corrigieron: "...de eternas laureolas / ceñidos, y los trate reverente / el tiempo"; pero Morata, sintiendo "bastante aventurada" esta enmienda, la rechaza y mantiene comedidos, que no es fácil de justificar. Mi conjetura es que comedidos es mala lectura por impedidos, otra palabra gongorina (cf. Soledad I, v. 284): los santos van 'ceñidos', 'rodeados' de aureolas.

134, v. 94: "pardas nubes"; la ed. de Alonso-Ferreres corrige "pardos nublos" con toda la razón del mundo, pues sólo con nublos se mantiene la asonancia $u$-o del romance. Morata se rinde a la evidencia e imprime "pardos nublos". (Tal vez sería mejor "pard[o]s nub[lo]s".)

Hay cuando menos dos casos en que, por falta de anotación en el aparato crítico, queda la duda de si se trata de malas lecturas del copista de $\mathbf{A}$ o de erratas modernas de imprenta ${ }^{8}$ :

8 Porque las hay: 49 "a sepulto" ("la sepulto"); 113, v. 12 "e donde" (“de donde"); 129, v. 28 “e zafiros" (“de zafiros”); 141, v. 48 "e que están” (“de que están”); 58 mno (mano); 65 tiste (triste); 111, v. 2 contemle (contemple); 14, var. del v. 13 ierno (ivierno); 118, epígrafe, incuitable (inevitable); 119, v. 7 "mas bajo" ("más bajo"); 125, v. 178 "mas bien" ("más bien”); 129, v. 49 "a Dios..., cúya es la gloria" ("cuya es"). Por lo general, Morata señala gráficamente las diéresis (crüel, etc.): así gloriosa en 130, v. 27, pero falta el signo en imperioso y en crïó (vv. 10 y 12 de esa misma canción), como falta en 127 , patrïarca (v. 4) y Josüé (v. 82), y también en Sḯn (121, v. 30, en contraste con el Sion monosílabo del v. 14). Hay versos en que 
113, v. 4: "[Salve, oh Roma], cuya frente... / reluces justamente". Es claro que hay que corregir: reluce.

133, v. 141: no intentas, sino intentáis, pues el poeta le está hablando de vos a la mujer flaca.

Como sucede con tantos poetas, hay en el caso de Luis Martín ciertos problemas de paternidad. He aquí lo que ocurre en cuatro de los sonetos:

1. "Cuando a su dulce olvido me convida...", atribuido a Luis Martín en E y en A, pero a Bartolomé Leonardo de Argensola en un ms. de la B.N.M. y como tal publicado en 1889 por La Viñaza, y en 1950 (en una sección de "poemas auténticos no incluidos en las Rimas") por José Manuel Blecua. Se extraña Morata de que Blecua haya cometido semejante desliz, pero ese ms. de la B.N.M. (el 4141) es muy serio. No está excluida la posibilidad de que la atribución de $\mathbf{E}$ y A sea la falsa. O sea que sobre este soneto queda, por ahora, una sombra de duda9 .

3. "Ven, que ya es hora, ven, amiga mía...", atribuido en $\mathbf{E}$ a "Pedro Luis Martín", seguramente errata, pero no podemos saber si por "Luis Martín" o por "Pedro Martín", ya que, como dice Morata en la p. 21, Pedro, "hermano (mejor que primo hermano) de Luis", era "también poeta". Y cf. infra, final de la nota 10.

11. "Por montes canos en el yerto invierno...", atribuido en $\mathbf{E}$ a "Luis Manuel de Figueroa". No sé por qué declara Morata que esta atribución tiene "escaso fundamento". Podría conjeturarse que "Luis Manuel" es error por "Luis Martín", pero ello no expli-

yo añadiría comas, por ejemplo en 5 (después de lumbre), en 24 (después de vuelo), en 77 (después de Subid) y en 135, v. 4 (después de defendéis). En cambio, creo que estorban las comas en 22 ("del campo verde / las hierbas"), en 125, v. 281 ("si llevas / premio") y en otros lugares. Si se quitan en 105 las tres comas de los v. 4 y 5 , la frase gana en claridad. En 77 imprime el editor: "Subid mi bien, subid, ¡oh Virgen bella! / más que el jazmín y... la rosa”; pero el signo de admiración en bella estorba la lectura (se entiende "Subid más que el jazmín y la rosa"). Obviamente hay que leer "¡oh Virgen, bella / más que el jazmín...”, etcétera.

${ }^{9} \mathrm{Si}$ se probara que es falsa la atribución a Bartolomé Leonardo, ésta quedaría de todos modos como testimonio de admiración por tan hermosa poesía. En su nota menciona Morata el soneto "Del sueño en las profundas fantasías..." (E, núm. 74), de autor incierto (¿Antonio Ortiz Melgarejo?). Hubiera podido decir, para reforzar la atribución de "Cuando a su dulce olvido..." a Luis Martín, que éste es muy aficionado al "soneto de sueño erótico", mencionando los sonetos 2, $3,6,8$ y 16. Lo malo es que en los últimos decenios del siglo xvi y en los primeros del XviI ese tipo de soneto fue cultivado por muchos otros poetas. 
caría el "Figueroa". Otra cosa es que no se sepa nada de Luis Manuel de Figueroa.

36. "Ahora que en tu rostro el suyo atento...", atribuido en $\mathbf{E}$ a "el Marqués del Aula”. Está en la misma situación que el soneto anterior; y también aquí dice Morata que la atribución tiene "escaso fundamento".

Por otra parte, al final del volumen edita Morata seis "Poesías de atribución dudosa”, entre las cuales hay otros cuatro sonetos (núms. 137-140): "Estas purpúreas rosas que al Aurora..." y "Brotando llamas de oro estos blandones...", atribuidos a Pedro Espinosa, el primero en E, el segundo en C, y en A a Luis Martín; "Tienen los Garamantes una fuente...", de "el Marqués de Tarifa" según E, de Luis Martín según A; y "Donde jamás el sol sus rayos tira...", del licenciado Juan de Aguilar según E, de Luis Martín según A. En verdad, no se ve muy bien la diferencia entre estos sonetos y los de la lista anterior. Los ocho son de atribución más o menos dudosa.

Las otras dos composiciones "de atribución dudosa” merecen consideración aparte:

141. "El triunfo es éste y éstos los cantares...", canción a Santa Úrsula y las Once Mil Vírgenes, sus compañeras de martirio. Los seis primeros versos y varios pasajes del resto son copia literal de la canción "A San Acacio" de Pedro de Jesús (o sea Pedro Espinosa), que figura en C, núm. 167. Espinosa había celebrado no sólo a San Acacio, sino también a los Diez Mil Soldados que, convertidos por él a la fe cristiana, sufrieron el martirio con él. Lo que hace Luis Martín es aprovechar todo aquello que se aplica por parejo a los dos multitudinarios martirios, igualmente gloriosos (con cambios como "Fuertes varones a quien Cristo toca...": "Vírgenes puras a quien Cristo toca...", etc.), y acudir a su propia cristiana Musa para lo mucho que atañe específicamente a las Once Mil. Creo que esta explicación es necesaria para entender el "chiste". Lo que dice Morata es que "Luis Martín mejora los resultados": ergo, está admitiendo que la canción a las Once Mil Vírgenes no es de "atribución dudosa" (cf. también p. 29, nota 4). Es, diría yo, un notable y original tour de force ${ }^{10}$.

${ }^{10}$ En los vv. 77-79: "De las bárbaras flechas negra lluvia / rompió en los aires once mil caminos / y vidas once mil hurtó a los años", imita Luis Martín el ingenioso soneto "A San Acacio" de Cristóbal de Villarroel (E, núm. 241): "De un golpe dio el Amor diez mil heridas, / de un solo arnés armó diez mil soldados...". -Es curioso el caso del soneto 102, estudiado por OtTo Jörder en ZRPh, 70 (1954), 98-103. Luis Martín lo escribió para festejar la visita de Lope de Vega a Antequera: "Her- 
142. "A dar gloriosos, en trofeos iguales...", canción a San Ignacio y San Francisco Javier que no figura en ninguna de las fuentes principales $\mathbf{E}, \mathbf{C}$ y $\mathbf{A}$ (o sea que está en la misma situación que las no dudosas poesías 86,103 y 135 ). En esa única fuente -un impreso sevillano de 1623- la canción se atribuye a "el licenciado Luis Martínez". Si Morata la imprime como dudosa es "por esa razón y por su escasa calidad". Pero el error "Martínez" por "Martín" es muy explicable y muy baladí, y la "escasa calidad", no infrecuente en este género tan retórico, tampoco es razón. No puede haber duda de que es una poesía auténtica.

Los párrafos del prólogo (pp. 41-44) que se ocupan de las traducciones de Horacio ofrecen una sucinta comparación entre Luis Martín y su "casi contemporáneo" Francisco de Medrano. Las versiones de éste se ciñen por lo general al texto de Horacio y son muy latinizantes. Las de Luis Martín, en cambio, son siempre parafrásticas y hablan en la lengua poética española (¿o andaluza? ¿o antequerana?) de los tiempos que corrían. Yo creo que, en vez de (o además de) comparar a Luis Martín con Medrano, habría que situarlo en su medio, o sea en el "círculo" de Pedro Espinosa, en compañía de los otros ocho traductores de Horacio. Espinosa estaba muy ufano de estos experimentos que sus contemporáneos estaban haciendo y que él ofrecía al lector para su deleite. Por algo en la portada misma de las Flores anuncia: "Van escritas diez y seis Odas de Horacio, traduzidas por diferentes y graves autores, admirablemente" (y en realidad no son 16, sino 18), y vuelve a la carga al final del prólogo: "De passo advertid que las Odas de Horacio son tan felices, que se aventajan a sí mismas en su lengua latina". Esta ponderación tenía que exasperar, forzosamente, al joven e intransigente Menéndez Pelayo (Horacio en España, 1877): "Nada más absurdo que este elogio aplicado a traducciones tan incorrec-

mosas ninfas, que en alegre coro / holláis a Guadalhorce las espaldas, / [escuchad] del extranjero cisne el dulce canto...", etc. Pero Lope, como dice el epígrafe de 101, "ingratamente lo puso en su libro del Peregrino [1604] con nombre de otro autor". En represalia, Luis Martín reelaboró el soneto, quitó a Lope y puso en su lugar a Juan Antonio Calderón: "Hermosas ninfas que al alegre coro / de vuestros pies de nieve ofrece espaldas / el Betis..., [escuchad] de vuestro nuevo cisne el dulce canto...", etc. No otra cosa hizo Luis Martín al convertir la canción de Espinosa "A San Acacio" en la suya a Santa Úrsula. Se trata de dos sonetos distintos. No hubiera estado mal imprimirlos por separado (naturalmente, con la advertencia de que el segundo figura en los preliminares de $\mathbf{C}$ a nombre de "Pedro Martín de la Plaza"). 
tas, parafrásticas y, digámoslo así, libérrimas, tan palabreras y poco horacianas". Es curioso, sin embargo, ver la pugna que en el espíritu de don Marcelino se trababa entre su horacianismo neoclásico y su gusto por la buena poesía. Dice: "así como no hay ninguna [traducción] perfecta, tampoco hay una sola que no demuestre mano de poeta”. Es claro que esta mano de poeta era lo que más contaba para Pedro Espinosa, tan buen apreciador, en sus tiempos, como Menéndez Pelayo en los suyos ${ }^{11}$. Podemos estar seguros de que, ante versos como los de la traducción del Diffugere nives por Luis Martín:
Pasó el helado y perezoso invierno, y ya la primavera con su bordada alfombra el campo cubre, y en el pimpollo tierno vuelve a nacer la verde cabellera que fue mesada del rigor de octubre,

lo primero que veía Menéndez Pelayo era que Horacio no dice "perezoso", ni "bordada alfombra", ni "pimpollo tierno", ni que la cabellera de los árboles "fue mesada del rigor de octubre". Para él, era ésta una traducción palabrera, despectivo sinónimo de "parafrástica”. Pero es claro que ni Espinosa ni Luis Martín sentían que traducción parafrástica fuera sinónimo de mala. Era una manera de traducir. Entre el horacianismo "clásico" de fray Luis de León y el horacianismo "neoclásico" de Moratín, Milá, Pombo, Burgos, etc., hubo un horacianismo "barroco", tan valioso, a su manera, como cualquier otro. Pero don Marcelino nunca abandonó su hostilidad a lo barroco. Por eso su juicio sobre los traductores de las Flores es tan anacrónico.

Además de las cinco traducciones de Horacio (dos en $\mathbf{E}$, dos en $\mathbf{C}$ y una sólo en $\mathbf{A}$ ), Luis Martín escribió otros poemas que

11 Marcelino Menéndez Pelayo, Bibliografia hispano-latina clásica, Madrid, 19501953, t. 6, pp. 92-93, dice que la traducción de Extremum Tanain es "por Luis Martín o Martínez de la Plaza", y la de Diffugere nives por "Luis Martínez de la Plaza", y aquí pone una nota: "El Martínez parece errata de la edición de Espinosa". Pero no hay tal. Lo que se lee en "la edición de Espinosa", o sea en las Flores, es que la traducción de Extremum Tanain es de "Luis Martín", y la de Diffugere nives es de "el mismo". Se tiene la impresión de que don Marcelino dedicó muy poca atención a este episodio de la historia de Horacio en España. Hay que añadir que en las Odas de Q. Horacio Flaco traducidas por más de treinta "ingenios españoles" (predominantemente por Javier de Burgos) y coleccionadas por Menéndez Pelayo, Maucci, Barcelona, 1908, se incluyen varias de las que aparecen en las Flores de Espinosa, entre ellas dos de Luis Martín: Extremum Tanain y Diffugere nives. 
demuestran su admiración por él: así, como señala Morata, el soneto 48, inspirado en el Extremum Tanain y en el Parcius iunctas $^{12}$; el 66, cuyo punto de partida es la oda Inclusam Danaen ${ }^{13}$, y la canción 115, elaboración del Diffugere nives con elementos del Solvitur acris. Parece habérsele escapado a Morata la canción 125, que comienza con una reminiscencia del Quem virum aut heroa ("Dime, Musa, de qué varón famoso / cantaremos...") y termina con un recuerdo del Diffugere nives ${ }^{14}$, evidentemente la oda predilecta de Luis Martín.

La traducciones de Ariosto, de Torquato Tasso y de otros italianos suelen ser tan "parafrásticas" como las de Horacio, no porque tengan mayor extensión que el original -puesto que se trata de sonetos-, sino porque también en ellas se sacrifica la literalidad en aras de la poesía, del buen sonido; lo que cuenta es también la "mano de poeta" 15 . El "concepto" de traducción que tiene Luis Martín no difiere mucho del de Góngora, ninguna de cuyas versiones (de Ariosto, de Tasso y de otros italianos) se ciñe al original ${ }^{16}$. Otra cosa son las siete traducciones de sonetos de Camões, en las cuales, naturalmente, era posible una mayor literalidad.

Las traducciones son homenajes de admiración a los poetas traducidos, lo mismo que las reminiscencias. Así homenajea Luis Martín a dos poetas españoles que a comienzos del siglo XVII eran ya "antiguos": Jorge Manrique y Garcilaso. El comienzo de la canción 111 ("Ya es tiempo que despierte / del sueño y que contemple el alma mía / cómo se pasa...", etc.) es rifacimento del de las inmortales Coplas. (Morata no señala esta reminiscencia, tal vez por obvia.) Los recuerdos de Garcilaso son más frecuentes. Por

12 Arturo Marasso, "Luis Martín de la Plaza”, Humanidades, La Plata, 1 (1921), p. 273, percibía en este "acorde" horaciano otra nota: la oda Audivere, Lice.

13 Caso parecido al del soneto 40, cuyo punto de partida es el Vivamus, mea Lesbia de Catulo. (Luis Martín es uno de los poquísimos españoles del siglo de oro que tuvieron oídos para Catulo.)

${ }^{14}$ La traducción dice (núm. 117, vv. 52 ss.): "Del heredero que tu muerte llama, / cuanto pudieres, quita; / siembra en la vida, cogerás el fruto / en la muerte; y la Fama...", etc. Cf. la canción 125, wv. 307 ss.: "Tú al heredero, que tu muerte llama / y en ruegos su presteza solicita, / cuanto pudieres quita, / y censo eterno te dará la Fama...".

${ }^{15}$ En nota al soneto 9, "En rota nave, sin timón ni antena...", dice Morata (sin comentario) que, según Lara Garrido, aquí Luis Martín "sigue de cerca" el "Passa la nave mia colma d'oblio..." de Petrarca. En realidad, salvo elementos que son lugar común (nave, borrasca, puerto), los dos sonetos son muy distintos.

${ }^{16}$ Cf. A. Alatorre, "Fama española de un soneto de Sannazaro", NRFH, 36 (1988), sobre todo pp. 966-972. 
ejemplo en 13: "Hoy, muerte, porque yo esperaba el fruto, / de un árbol tierno cortas los despojos...” (cf. soneto XXV); en 21: “...ejecutad, señora, / vuestra crueldad en el que veis rendido" (cf. soneto II); y en 121, v. 20: "dulces y alegres cuando Dios quería" (cf. soneto $\mathrm{X}$ ).

Luis Martín rinde homenaje también a poetas nada "antiguos" sino, por el contrario, modernísimos: compañeros de oficio. Salta a la vista su afinidad con Pedro Espinosa ${ }^{17}$. Pero el contemporáneo más admirado es sin duda Góngora. Habría que desarrollar lo que sobre esto dice Morata en las pp. 28-31 de la introducción y en sus notas a los núms. 44, 51, 80, 83, 86, 96, 124 y 128. Sólo a propósito de 80 señala Morata (nota respectiva, y pp. 28-29) el modelo preciso, que es el soneto 248 de Góngora (ed. Millé). En los demás casos se limita a decir: "claramente se percibe la influencia...", "soneto honda y delicadamente gongorino", "soneto de arranque gongorino", etc. Pero valdría la pena hilar más delgado. (Y transcribo los apuntes que fui haciendo durante mi lectura.) Vocabulario gongorino: perdonar a (69), "troncar flores" (88), reducir 'hacer volver' (104), etc. Frases gongorinas: "en peñas no, en mi rostro sí señales" (45), "lo sella un mármol, una tumba encierra" (124, v. 56), etc. Hipérbaton: "la confusión penetra del desierto" (78), "de cuantas le tributan claras fuentes / bellísimo ostentó de ninfas coro" (128, vv. 5-6), etc. Acusativo griego: "un enebro, crespo la maraña" (78). Empleo de que su en vez de cuyo: "el Reno, / que sauces y espadañas son su ropa" $(141, \text { v. } 17)^{18}$. Versos enteros: "ayer nació para morir mañana" (97: cf. Góngora, soneto XCIV), "el padre de las ondas Ocëano" (128, v. 49; igual en la Soledad I, v. 405). Caso muy especial es el del romance 134, "Aparte, la mi señora, / de las orejas los tufos...”, una de las pocas composiciones humorísticas de Luis Martín, que toma la materia del romancillo "Noble desengaño...", y la forma del romance "La ciudad de Babilonia...": gran parte de las asonancias en ú-o proceden de Góngora: tufos, testuzo, trabuco, pantuflo, chuzo, nublo, grullo, etcétera ${ }^{19}$.

17 Desde el punto de vista métrico, el único poema anómalo de Luis Martín es el rotulado "Psalmo", núm. 120 ("Venid, oh castas vírgenes..."), especie de silva (o proto-silva) de 63 versos, 30 de ellos sueltos (y esdrújulos 8 de los 30). Es imitación estructural de una "proto-silva" de Espinosa. Cf. A. Alatorre, "Quevedo: de la silva al ovillejo", HEA, pp. 20-22.

18 Cf. A. Alatorre, "Notas sobre las Soledades", NRFH, 44 (1996), p. 75 (perdonar a y acusativo griego) y pp. 89-90 (que su 'cuyo').

${ }^{19}$ En nota al v. 82, "librado un pie como grullo", señala Morata una reminiscencia concreta: "librada en un pie toda sobre él pende" (Polifemo, v. 258), 
Todos los ejemplos del párrafo anterior proceden de A (Cancionero antequerano): ninguna de las respectivas poesías está en las Flores de Espinosa (E), impresas en 1605, ni en las de Calderón $(\mathbf{C})$, recopiladas en 1611. Es lógico suponer que esas poesías de $\mathbf{A}$ son posteriores. ¿Quiere esto decir que Luis Martín percibió el encanto de Góngora en época tardía? Así lo da a entender Morata. En la p. 28 dice: "La aparición de los grandes poemas gongorinos... influye profundamente en Luis Martín", o sea que su gongorismo sería posterior a 1613. Y en el núm. 80 comenta que este soneto, de 1622, está escrito "ya bajo el imperio estético de Góngora". Creo que el asunto merece ser visto más de cerca. $Y a$ en 1611, antes de que Góngora comenzara, casi subrepticiamente, a distribuir copias del Polifemo y las Soledades entre contados amigos, Luis Martín estaba gongorizando: imitaba ya el vocabulario, el ritmo, la musicalidad, la sintaxis de Góngora (el Góngora de entonces, por supuesto; el anterior al escándalo; el aún no imitado; el Góngora compañero de oficio). Ejemplos: 10, "Subiendo en la mitad del cielo ardía, / usando de su oficio generoso, / el sol...” (Góngora, núm. 221: "Raya, dorado sol..., / y usando al esparcir tu nueva lumbre / tu generoso oficio y real costumbre..."); 35, "mas luego que del sol..." (Góngora, núm. 219: "mas luego que ciñó..."); 55, "Rey de esotros metales, oro puro..." (Góngora, núm. 226: "Rey de los otros, río caudaloso..."); 93, "émulo al rayo que mejor se atreve / al árbol más hermoso y levantado..."; y 94, "la corona / que el tiempo no combate su firmeza" (que su=cuyo). Y si nos remontamos a 1603, año en que quedaron reunidas las Flores de Espinosa, hallamos lo mismo: 5, "Segundo honor del cielo cristalino...", el soneto todo ${ }^{20}$, y concretamente el v. 8, "y válgame tu lumbre, peregrino" (Góngora,

pero no se acuerda de "pendiente en un pie a lo grullo" ("La ciudad de Babilonia", v. 398). En la nota inicial dice: "Este eficacísimo romance... en nada desmerece al lado de los tratamientos análogos de Góngora o Quevedo”. Yo no veo en él nada específicamente quevedesco. Donde sí está muy presente Quevedo es en los poemas 133 y 136 (los únicos que Luis Martín hizo en quintillas).

${ }^{20}$ Es un soneto "optativo"; el poeta le pide un favor a la Luna y le desea, a cambio de él, lo mejor posible: "[iOh Luna, alumbra mi camino!]: así en el mar te mires siempre llena...", etc. Cf. Góngora, núm. 229: “¡Fragoso monte, [esconde esos nombres grabados en los troncos!]: asícubra de hoy más cielo sereno...”; y núm. 242: "[iOh álamos, llorad mi atrevimiento!]: así del sol estivo el rayo ardiente...”, etc. Véase también el 18 de Luis Martín: “¡Oh... húmedo Noto, [conduce a puerto esa nave!]: asínunca jamás el cierzo airado...”; y el 102: “¡Hermosas ninfas, [escuchad al cisne que ha llegado!]: asi miréis con inmortal decoro...", etc. El 32 y el 69 son asimismo sonetos "optativos". 
núm. 256: "y ampáreme tu sombra, peregrino"); 32, "Reina de esotras flores, fresca rosa...”; y 34, “ ¡Oh noble suspensión de mi tormento...!" (Góngora, núm. 240: "gloriosa suspensión de mi tormento"). Ya en 1603 gongorizaba Luis Martín.

"Luis Martín -dice Morata, p. 31-, aunque tome a menudo [a Góngora] como referencia [sic], no es un poeta gongorino". Claro que no lo es en el mismo sentido en que lo son, por ejemplo, Soto de Rojas y Villamediana. Pero los pasajes que he citado nos lo muestran como el primer seguidor que tuvo Góngora ${ }^{21}$. Si algún día se reúne una Antología poética en honor de Góngora más esmerada que la que en 1927 publicó Gerardo Diego, el primer lugar, en orden cronológico, tendrá que corresponderle a Luis Martín de la Plaza22.

He aquí, para terminar, unas pocas minucias:

Comentando el verso "la hermosa ocasión de mi tormento" (8) observa Morata que Luis Martín “y, en general, todos los poetas antequeranos", aspiran la $h$ - procedente de $f$ - latina. Habría que decir andaluces en vez de antequeranos, y explicar que la aspiración era todavía normal en poetas castellanos como Garcilaso y fray Luis de León. Morata señala estas aspiraciones de manera poco sistemática (no dice nada sobre "hija de la tierra" en 3, ni sobre "hacha ardiente" en 4, etc.). De la misma manera observa que en "de Dánae el honor y la hermosura" (66) la $h$-de hermosura no se aspira (hubiera podido observarlo ya en 29: "de tu hermosura el interés tan cierto"). Yo creo que hubiera sido mejor dedicar unas líneas de la introducción a estos aspectos fonéti$\cos ^{23}$, omitiendo las observaciones esporádicas. (Y no estaría de más advertir que descuido, en 134, v. 42, se pronuncia descúido, con

${ }^{21}$ Hay que reconocer que Menéndez Pelayo, op. cit., p. 92, se dio cuenta de esto. Entre los poetas de las Flores de Epinosa -dice- "algunos, como Luis Martín, se dan la mano con la escuela de Góngora”. Pero es claro que en 1603 no había aún tal escuela.

22 Quizá no esté de más una aclaración. En rigor, los primeros "gongoristas" fueron los poetas -anónimos- que imitaron los juveniles romances y letrillas de Góngora publicados durante los dos últimos decenios del siglo XVI en las varias Flores de romances (ejemplo insigne, las imitaciones de "Hermana Marica"). Luis Martín no imita a ese Góngora "ligero", sino al "serio".

${ }^{23}$ La regla general es, como en Góngora, la aspiración. Luis Martín aspira la h-de hacer, hacha, hallar, hambre, herir, hermoso, hijo, hilo, himno (!), hinchado, hondo, horadar, huir (y ahuyentar), humo y hurtar. Las excepciones ocasionales son pocas: (h)icieron (134, v. 40), (h)allar (43 y 53) y (h)ermosura (29, 35, 66 y 130, v. 21). También en las Soledades hay excepciones ocasionales: (h)ermoso, (h)allar, (h)erir. (Cf. mis "Notas sobre las Soledades", p. 65.) 
el acento en la $u$, igual que en "La ciudad de Babilonia", v. 338: la asonancia es $u-o$.)

"La ortografía -dice Morata, p. 58- se ha actualizado por completo: sólo razones métricas han determinado el mantenimiento de algún arcaísmo como vide o vido". Y en nota al verso final de 2 ("huyó, toqué la cama, vide el día") vuelve a excusarse de haber violado su propia regla: "No se moderniza el arcaísmo vide, para respetar el cómputo silábico". Otro "arcaísmo" sería el arena (122, v. 149), imposible de cambiar en la arena a causa del "cómputo silábico". Pero cuando el cómputo no obsta, Morata moderniza: en "os trajo al puerto" (72, v. 13) "actualizo el arcaísmo trujo", etc. Yo pienso que este empleo del rótulo arcaísmo es inadecuado. Si Luis Martín dijera fincades, atrevudo, vegada y pescudar en vez de quedáis, atrevido, vez y preguntar, eso sí sería arcaísmo, pues eran formas ya desusadas; pero si dice lo que sus contemporáneos decían, como vide y trujo, eso no es arcaísmo. Por lo demás, ningún lector medianamente familiarizado con Cervantes, Lope o Góngora va a sufrir si se topa con mesmo, cudicia, escuro, conduzga, dende, etc. (o con ivierno, proprio, invidia, etc.). Sustituir las formas de comienzos del siglo xvII por las actuales es un anacronismo. Estará bien imprimir voz en lugar de boz o envidia en lugar de embidia ${ }^{24}$, pero no parece bien modernizar unas veces concepto (cuando está en mitad de verso) y dejar otras veces conceto (cuando rima con discreto). A pesar de que en el soneto $9 \mathrm{el}$ "texto base" dice entena, tan normal en los siglos de oro, Morata imprime antena. Se decía campión, y Morata imprime campeón (v. 31 de 129). En nota a crin dorado (15) dice: "Es poco correcto el sustantivo crin como masculino". Este "poco correcto" es también anacronismo: no sólo era frecuente el crin (también en 18), sino que era, probablemene, más "poético" (más italiano) que la crin.

En la p. 45 observa Morata que la gran mayoría de los sonetos de Luis Martín (101 del total de 108) tienen esta estructura en los tercetos: $\mathrm{CDE}$ CDE; las únicas excepciones que ha hallado son CDC DCD en cinco sonetos y CDE DEC en dos. En realidad, los

${ }^{24}$ En el mismo caso que embidia está embestir (42, 86 y 130, v. 14), cuya "ortografía” debiera aquí ser envestir (forma registrada en el DRAE): la Aurora, por ejemplo, no embiste, sino enviste ('reviste', 'recubre') de rocío a los lirios. Comentando dos casos de envestir (uno de ellos de la Celestina: "envestir las caras con ungüentos") dice Corominas que se trata de acepciones "directamente derivadas de la idea de 'revestir', y en realidad deben considerarse vocablo independiente [de embestir]". 
tercetos CDE CDE son sólo 96; y las otras formas no son dos, sino cinco: CDE CED (140), CDE DEC (37y 48), CDC DCD (22, 40, 46, 71 y 96$)$, CDE DCE ( 1 y 49) y CDE ECD ( 5 y 7 [pero si en 7 se adopta la variante, sería también CDE DCE]). En su predilección por CDE CDE coincide Luis Martín con Cetina, Acuña, Cueva, Aldana, Mosquera, Liñán y sobre todo Herrera. En Góngora, en cambio, esa forma no llega al $50 \%$.

Antonio Alatorre

El Colegio de México 